\title{
EFICIÊNCIA NO USO DA ÁGUA NA CANA-DE-AÇÚCAR SOB DIFERENTES LÂMINAS DE IRRIGAÇÃO E NÍVEIS DE ZINCO NO LITORAL PARAIBANO ${ }^{1}$
}

\author{
CARLOS H. A. FARIAS ${ }^{2}$, PEDRO D. FERNANDES ${ }^{3}$, JOSÉ DANTAS NETO ${ }^{4}$, \\ HANS R. GHEYI ${ }^{5}$
}

RESUMO: Esta pesquisa foi conduzida em área experimental da Fazenda Capim II, localizada no Município de Capim - PB, com o intuito de determinar a eficiência no uso da água (EUA) pela cana-de-açúcar (Saccharum officinarum L.), cultivar SP 79-1011. O delineamento experimental consistiu em blocos casualizados, com três repetições, em esquema fatorial 5 x 5 . Os tratamentos referentes à lâmina de irrigação foram: sequeiro; 25; 50; 75 e 100\% da ETc $(1.026,57 \mathrm{~mm})$ com as respectivas precipitações efetivas de 780,06;713,31;487,54;243,71 e 194,51 mm; os níveis de zinco estudados foram $0 ; 1 ; 2 ; 3$ e $4 \mathrm{~kg} \mathrm{ha}^{-1}$. O equipamento de irrigação utilizado foi do tipo pivô central, com turno de rega de nove dias. A eficiência no uso da água (EUA) na produção de colmos e de açúcar aumenta à medida que se eleva a lâmina total de água aplicada à cultura. Para a região norte-paraibana dos tabuleiros costeiros, a EUA na produção de colmo e de açúcar, de forma maximizada, é 7,12 e $0,67 \mathrm{~kg} \mathrm{~m}^{-3}$, respectivamente.

PALAVRAS-CHAVE: Saccharum officinarum, otimização, zinco, evapotranspiração.

\section{WATER USE EFFICIENCY IN SUGARCANE CROP UNDER DIFFERENT DEPTHS OF IRRIGATION AND ZINC DOSES IN COASTAL REGION OF PARAÍBA, BRAZIL}

\begin{abstract}
The study was conducted in an experimental area of the Capim II Farm, located in the municipality of Capim - PB, Brazil, with the objective of determining the efficiency in the use of the water (WUE) for the sugarcane crop (Saccharum officinarum L.), cultivar SP 79-1011. The experimental design consisted of randomized blocks, with three replications in a $5 \times 5$ factorial design. The irrigation treatments were: rainfed; $25 ; 50 ; 75$ and $100 \%$ of the ETc $(1,026.57 \mathrm{~mm})$ with the respective effective precipitations of $780.06 ; 713.31 ; 487.54 ; 243.71$ and $194.51 \mathrm{~mm}$. The levels of zinc studied were $0 ; 1 ; 2 ; 3$ and $4 \mathrm{~kg} \mathrm{ha}^{-1}$. The irrigation equipment used in the study was a central pivot with irrigation frequency of nine days. The water use efficiency (WUE) of sugarcane crop in terms of cane production and of sugar increased with the depth of water applied. For the Coastal Table Lands of northern Paraiba, the maximized WUE for sugarcane and sugar production is 7.12 and $0.67 \mathrm{~kg} \mathrm{~m}^{-3}$, respectively.
\end{abstract}

KEYWORDS: Saccharum officinarum, optimization, irrigation, zinc, evapotranspiration.

\section{INTRODUÇÃO}

O suprimento adequado de água é essencial para o crescimento e o desenvolvimento da canade-açúcar, com demanda em torno de $1.200 \mathrm{~mm}$ ao ano (BLACKBURN, 1984). Segundo DOORENBOS \& KASSAM (1979), a demanda hídrica da cultura está entre 1.500 e $2.500 \mathrm{~mm}$. Conforme ALFONSI et al. (1987), nas áreas canavieiras do Brasil, o total de precipitação pluviométrica anual varia de 1.100 a $1.500 \mathrm{~mm}$; portanto, para que se possam obter produtividades favoráveis próximas às do potencial genético da cultura, com o auxílio da irrigação, faz-se necessário conhecer a sua demanda hídrica e o respectivo coeficiente do cultivo (kc), que, no caso da cana, foi determinado por DOOREMBOS \& KASSAM (1979). De acordo com esses autores, com irrigação nos trópicos e subtrópicos secos, a eficiência no uso da água pela cultura, em solos com $80 \%$ de água disponível, varia de 5 a $8 \mathrm{~kg} \mathrm{~m}^{-3}$ em termos de colmos, e de 0,6 a $1 \mathrm{~kg} \mathrm{~m}^{-3} \mathrm{em}$ sacarose.

\footnotetext{
Extraído da tese de doutorado do primeiro autor.

${ }^{1}$ Pesquisador, Dr. Destilaria Miriri S.A., Fazenda Miriri, Santa Rita - PB, carlos.henrique@miriri.com.br

${ }^{2}$ Prof. Dr., Universidade Federal de Campina Grande, Departamento de Engenharia Agrícola, pdantas@deag.ufcg.edu.br

${ }^{3}$ Prof. Dr., Universidade Federal de Campina Grande, Departamento de Engenharia Agrícola, zedantas@deag.ufcg.edu.br

${ }^{4}$ Prof. Dr., Universidade Federal de Campina Grande, Departamento de Engenharia Agrícola, hans@deag.ufcg.edu.br

Recebido pelo Conselho Editorial em: 15-8-2007
}

Aprovado pelo Conselho Editorial em: 30-9-2008 
Para BARRACLOUGH \& CO (1999), a eficiência no uso da água $\left(\mathrm{kg} \mathrm{m}^{-3}\right)$ é definida como a relação entre a produtividade da cultura $\left(\mathrm{kg} \mathrm{ha}^{-1}\right)$ e o volume total de água consumido nos processos fisiológico de produção $\left(\mathrm{m}^{3} \mathrm{ha}^{-1}\right)$.

Além de ser o principal constituinte do protoplasma, a água participa diretamente de muitas reações químicas, que são responsáveis pela turgescência celular. Portanto, a redução na sua absorção tem como conseqüência a desidratação celular, comprometendo, assim, os processos fisiológicos e os componentes do crescimento (PÁEZ et al., 1995). O estresse hídrico resulta em redução gradativa do potencial osmótico da água na célula, em função de seu baixo conteúdo hídrico e conseqüente aumento na concentração de solutos; esse fenômeno é denominado "ajustamento osmótico" e pode conferir à planta manutenção completa ou parcial do turgor (HATE \& ORCUTT, 1987).

As plantas estão sujeitas a grande variedade de estresses ambientais, incluindo temperaturas inadequadas, condições físico-químicas de solo desfavoráveis e várias doenças e pragas; contudo, pode-se dizer que o déficit hídrico reduz o crescimento e a produtividade vegetal, mais que todos os outros estresses combinados, pois ocorre em qualquer local, mesmo nas regiões consideradas úmidas (KRAMER, 1983). Para TAIZ \& ZEIGER (2002), o déficit hídrico não é limitado apenas às regiões áridas e semi-áridas, pois, mesmo em regiões consideradas climaticamente úmidas, ocorrem períodos em que a distribuição irregular das chuvas limita o crescimento das plantas.

KRAMER (1983) cita que o déficit hídrico se desenvolve durante períodos em que a perda de água por transpiração excede os ganhos por absorção. Para ele, o déficit hídrico na cana-de-açúcar pode ser causado tanto pela perda excessiva de água quanto por baixa absorção hídrica; pode ocorrer, ainda, pela associação dos dois processos, tendo o fator climático papel dominante no crescimento da cultura.

A classificação dos nutrientes minerais, de acordo com sua função metabólica, põe o zinco no grupo 4, o mesmo grupo de cobre, ferro, níquel e molibdênio, todos eles envolvidos em reações de redox e transporte de elétrons (TAIZ \& ZEIGER, 2002), que influenciam diretamente no crescimento da planta. Do ponto de vista de fertilidade do solo, CARRIJO et al. (2004) citam que, para os nutrientes com forte interação com a matriz do solo e que, predominantemente, se movimentam por difusão, como é o caso do zinco, o aumento da umidade do solo, com a utilização de tecnologia de irrigação por gotejamento, melhora a eficiência da adubação, especialmente em solos arenosos.

Não se encontraram, na literatura, informações sobre o uso de Zn em cana-de-açúcar; já em milho, SOARES (2003), estudando efeitos de interações entre zinco, boro e nitrogênio na produtividade, observou não ter o $\mathrm{Zn}$ interferido de forma significativa em número de folhas, índice de área foliar, comprimento do primeiro internódio do colmo e matéria seca do pendão.

Neste trabalho, teve-se o objetivo de estudar o comportamento da cultura da cana-de-açúcar cultivada em tabuleiro costeiro paraibano e submetida a diferentes lâminas de irrigação e níveis de adubação com zinco, no tocante a sua eficiência no uso da água (EUA), tanto na produção de colmos (matéria-prima), como na produção de açúcar (qualidade da matéria-prima).

\section{MATERIAL E MÉTODOS}

O experimento foi conduzido na Fazenda Capim II (latitude 6054'59,88's, longitude $35^{\circ} 09^{\prime} 17,86^{\prime \prime} \mathrm{W}$ e altitude de $121 \mathrm{~m}$ ), localizada no município de Capim - PB (Figura 1A), no período de setembro de 2004 a setembro de 2005, com a cultivar SP 79-1011 de cana-de-açúcar (Saccharum officinarum L.), com potencial para atingir produtividade média, na região do litoral norte paraibano, de 69,00 $\mathrm{t} \mathrm{ha}^{-1}$; é uma cana precoce e de alta adaptabilidade, recomendada para áreas de média a baixa fertilidade, com colheita nos meses de setembro a novembro (NUNES JÚNIOR et al., 2003). Dentre suas principais características industriais, destacam-se: fibra 14,7\%, PCC $10,5 \%$, pureza $79,74 \%$ e sólidos solúveis totais ( ${ }^{\circ}$ brix) da ordem de 16,10\% (RIDESA, 2003). 
Estudou-se, nesta pesquisa, a eficiência no uso da água (EUA) pela cultura da cana-de-açúcar quando submetida a lâminas de irrigação, em termos de fração da ETc (sequeiro; 25; 50; 75 e 100\% da ETc.) e níveis de adubação com zinco $\left(0 ; 1 ; 2 ; 3\right.$ e $\left.4 \mathrm{~kg} \mathrm{ha}^{-1} \mathrm{de} \mathrm{Zn}\right)$, tendo, como fonte, o sulfato de zinco heptaidratado $\left(\mathrm{ZnSO}_{4} \cdot 7 \mathrm{H}_{2} \mathrm{O}\right)$, com $22 \%$ do elemento, sendo aplicados, respectivamente, as seguintes quantidades do produto 0,$00 ; 4,54 ; 9,00 ; 13,63$ e $18,18 \mathrm{~kg} \mathrm{ha}^{-1}$.

A EUA foi definida como sendo a relação entre a produtividade e o volume total de água utilizada na produção, conforme eqs.(1) e (2):

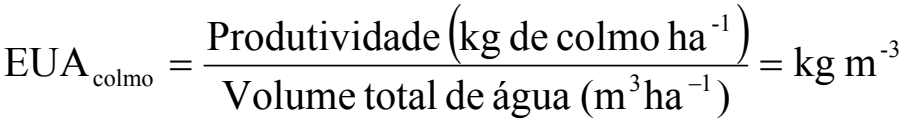

$$
\begin{aligned}
& \text { EUA }_{\text {açúcar }}=\frac{\text { Produtividade }\left(\mathrm{kg} \text { de açúcar ha }{ }^{-1}\right)}{\text { Volume total de água }\left(\mathrm{m}^{3} \mathrm{ha}^{-1}\right)}=\mathrm{kg} \mathrm{m}^{-3}
\end{aligned}
$$

O delineamento experimental foi composto de blocos casualizados, em esquema fatorial 5 x 5, com três repetições. A área foi subdividida em cinco setores de irrigação, cada um com cinco parcelas de adubação com zinco. O experimento contou com área vizinha, fora do raio de alcance da irrigação pelo pivô, para a implantação do tratamento de sequeiro, conforme demonstrado na Figura 1B (sem irrigação).

As parcelas foram formadas por nove fileiras de cana-de-açúcar (espaçamento de 1,20 m), com $12 \mathrm{~m}$ de comprimento (9 linhas x $12 \mathrm{~m}$ ); como área útil para a coleta de dados, tanto para as amostras mensais como para a amostragem final, foi considerada a área central $(10 \mathrm{~m})$ das sete fileiras no meio da parcela.

A

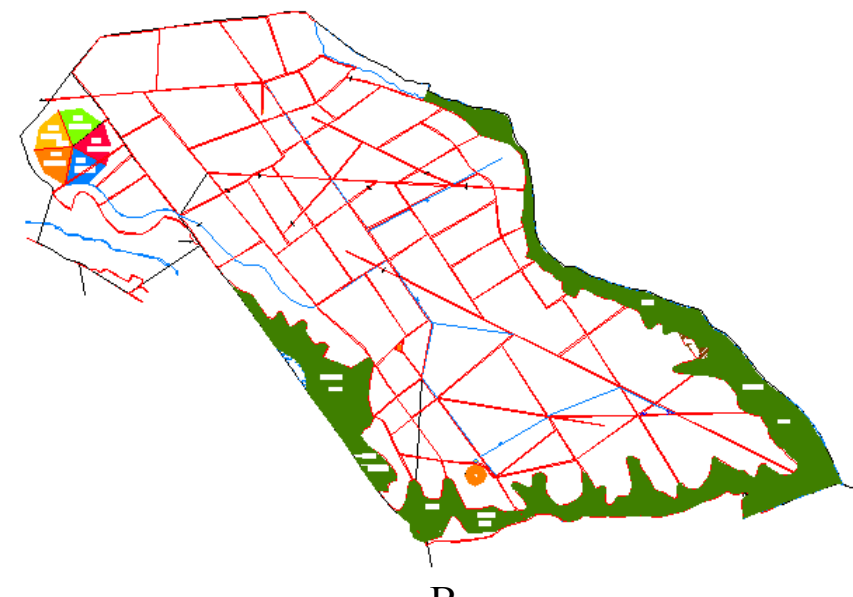

$\mathrm{B}$
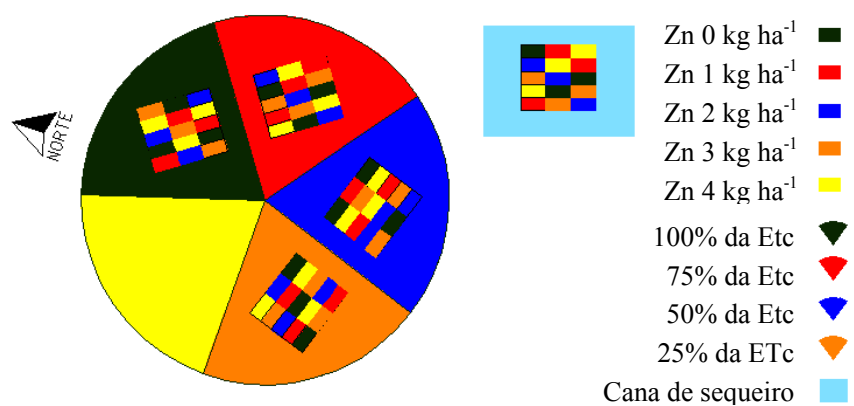

FIGURA 1. (A) Mapa de localização da Fazenda Capim II, (B) área do experimento e tratamentos. (A) Localization of Capim II Farm, (B) area of experiment and treatments. 
O solo predominante na fazenda é do tipo Argissolo Vermelho-Amarelo distrófico, de acordo com a classificação proposta por EMBRAPA (1999); o clima é classificado como As', segundo Köeppen, quente e úmido, com chuvas de outono a inverno, temperatura média anual de $28^{\circ} \mathrm{C}$, com precipitação média anual de $1.200 \mathrm{~mm}$, verificando-se seis meses secos. Nas Tabelas 1 e 2, apresentam-se, respectivamente, as características físico-hídricas e químicas do solo, e a análise química da água de irrigação, nas quais se observam os valores de capacidade de campo e ponto de murcha, que caracterizam turno de rega de nove dias, teor de zinco (tido como baixo) e qualidade da água $\mathrm{C}_{1}$.

TABELA 1. Análise físico-hídrica e química do solo da área do experimento com a cultura da canade-açúcar. Hidro-Physical and chemical analysis of soil of the experimental area of sugarcane crop.

\begin{tabular}{|c|c|c|c|}
\hline \multirow{2}{*}{ Características do Solo } & \multicolumn{3}{|c|}{ Profundidade (cm) } \\
\hline & $0-20$ & $21-50$ & $51-100$ \\
\hline \multicolumn{4}{|l|}{ Granulometria (\%) } \\
\hline Areia & 73,00 & 68,86 & 55,64 \\
\hline Silte & 3,75 & 3,77 & 9,86 \\
\hline Argila & 23,25 & 27,37 & 33,50 \\
\hline Textura & FAA & FAA & FAA \\
\hline \multicolumn{4}{|l|}{ Densidade $\left(\mathrm{kg} \mathrm{dm}^{-3}\right)$} \\
\hline Aparente & 1,40 & 1,40 & 1,33 \\
\hline Real & 2,71 & 2,67 & 2,66 \\
\hline Porosidade (\%) & 48,33 & 47,56 & 50,00 \\
\hline \multicolumn{4}{|l|}{ Umidade (volume) } \\
\hline 0,33 (bar) & 6,37 & 9,37 & 14,84 \\
\hline 15,00 (bar) & 3,88 & 5,69 & 9,11 \\
\hline Água disponível (\%) & 2,49 & 3,68 & 5,73 \\
\hline \multicolumn{4}{|c|}{ Complexo sortivo $\left(\mathrm{cmol}_{\mathrm{c}} \mathrm{dm}^{-3}\right)$} \\
\hline Cálcio & 1,97 & 1,45 & 1,51 \\
\hline Magnésio & 2,46 & 3,19 & 3,85 \\
\hline Sódio & 0,01 & 0,01 & 0,01 \\
\hline Potássio & 0,01 & 0,02 & 0,005 \\
\hline Soma de bases & 4,45 & 4,67 & 3,87 \\
\hline Hidrogênio & 0,79 & 0,92 & 0,26 \\
\hline Alumínio & 0,20 & 0,40 & 0,40 \\
\hline CTC & 5,44 & 5,99 & 6,03 \\
\hline Carbono orgânico (\%) & 0,40 & 0,41 & 0,38 \\
\hline Matéria orgânica $(\%)$ & 0,69 & 0,71 & 0,65 \\
\hline Nitrogênio (\%) & 0,04 & 0,04 & 0,03 \\
\hline Fósforo $\left(\mathrm{mg}^{100 \mathrm{~g}^{-1}}\right)$ & 1,14 & 0,75 & 0,08 \\
\hline $\mathrm{pH}\left(\mathrm{H}_{2} \mathrm{O}\right)$ & 6,80 & 5,36 & 4,71 \\
\hline $\mathrm{CE}\left(\mathrm{dS} \mathrm{m} \mathrm{m}^{-1}\right)$ & 0,13 & 0,10 & 0,08 \\
\hline Zinco (mg kg $\left.{ }^{-1}\right)$ & 0,90 & 0,80 & 0,5 \\
\hline Cobre $\left(\mathrm{mg} \mathrm{kg}^{-1}\right)$ & 1,40 & 1,20 & 1,00 \\
\hline Ferro $\left(\mathrm{mg} \mathrm{kg}^{-1}\right)$ & 120,00 & 140,00 & 155,00 \\
\hline Manganês (mg kg $\left.{ }^{-1}\right)$ & 2,50 & 1,50 & 0,90 \\
\hline
\end{tabular}


TABELA 2. Análise química da água utilizada na irrigação da área do experimento. Chemical analysis of water used in the irrigation of experiment area.

\begin{tabular}{|c|c|}
\hline Características Químicas da Água & Valor \\
\hline $\mathrm{pH}$ & 6,20 \\
\hline Condutividade elétrica $\left(\mu \mathrm{S} \mathrm{cm}^{-1}\right)$ & 110 \\
\hline \multicolumn{2}{|l|}{ Ílons $\left(\mathrm{mmol}_{\mathrm{c}} \mathrm{L}^{-1}\right)$} \\
\hline Cálcio & 0,22 \\
\hline Magnésio & 0,43 \\
\hline Sódio & 0,55 \\
\hline Potássio & 0,07 \\
\hline Cloretos & 0,65 \\
\hline Sulfatos & Ausência \\
\hline Bicarbonatos & 0,23 \\
\hline Carbonatos & 0,00 \\
\hline Relação de adsorção de sódio - RAS $\left(\mathrm{m} \mathrm{mol} \mathrm{L}^{-1}\right)^{0,5}$ & 0,96 \\
\hline Classe de água & $\mathrm{C}_{1}$ \\
\hline
\end{tabular}

A irrigação deu-se via pivô central fixo, com área de 27 ha e comprimento de 257,4 $\mathrm{m}$ do centro do pivô até a última torre, com raio irrigado de $290 \mathrm{~m}$, em velocidade máxima de $127 \mathrm{~m} \mathrm{~h}^{-1}$, quando o percentímetro estava regulado em $100 \%$. O conjunto eletrobomba é formado por um motor $\mathrm{WEG}^{\circledR}$ de $55,162 \mathrm{~kW}$ e uma bomba $\mathrm{KSB}^{\circledR}$ com vazão de $0,048 \mathrm{~m}^{3} \mathrm{~s}^{-1}$.

Determinaram-se as lâminas de irrigação a partir da evapotranspiração de referência (ETo) a partir do tanque Classe A. Os níveis de irrigação foram definidos, em termos percentuais, em relação à evapotranspiração da cultura (ETc), sendo as irrigações realizadas em um turno de rega de nove dias. Na Figura 2, estão representadas, graficamente, as lâminas aplicadas em cada tratamento e as principais variáveis climáticas registradas no local. Nota-se que o período foi marcado por ciclo muito longo de estiagem e estação chuvosa muito curta, concentrada nos meses de maio, junho e julho (Figura 2C).

A construção da curva de controle do equipamento deu-se após um ensaio preliminar, sendo definida a vazão com um hidrômetro instalado na entrada do pivô; determinou-se, também, o raio irrigado $(\mathrm{m})$, contando com o canhão hidráulico no lance final. O levantamento de campo possibilitou o cálculo matemático do tempo de giro $(\mathrm{Tg})$ quando o relé percentímetro estava regulado em $100 \%$.

$$
\operatorname{Tg}=\frac{2 \pi r}{V}
$$

em que,

$\mathrm{r}$ - raio do pivô até a última torre, $\mathrm{m}$, e

$\mathrm{V}$ - velocidade do pivô (última torre), $\mathrm{m} \mathrm{h}^{-1}$.

A determinação da lâmina bruta aplicada pelo equipamento, quando regulado em $100 \%$, foi feita conforme a eq.(4):

$$
\mathrm{Lb}=\frac{\mathrm{Q} T g}{10 \mathrm{~A}}
$$

em que,

$\mathrm{Q}$ - vazão, $\mathrm{m}^{3} \mathrm{~s}^{-1}, \mathrm{e}$
A - área irrigada, ha. 

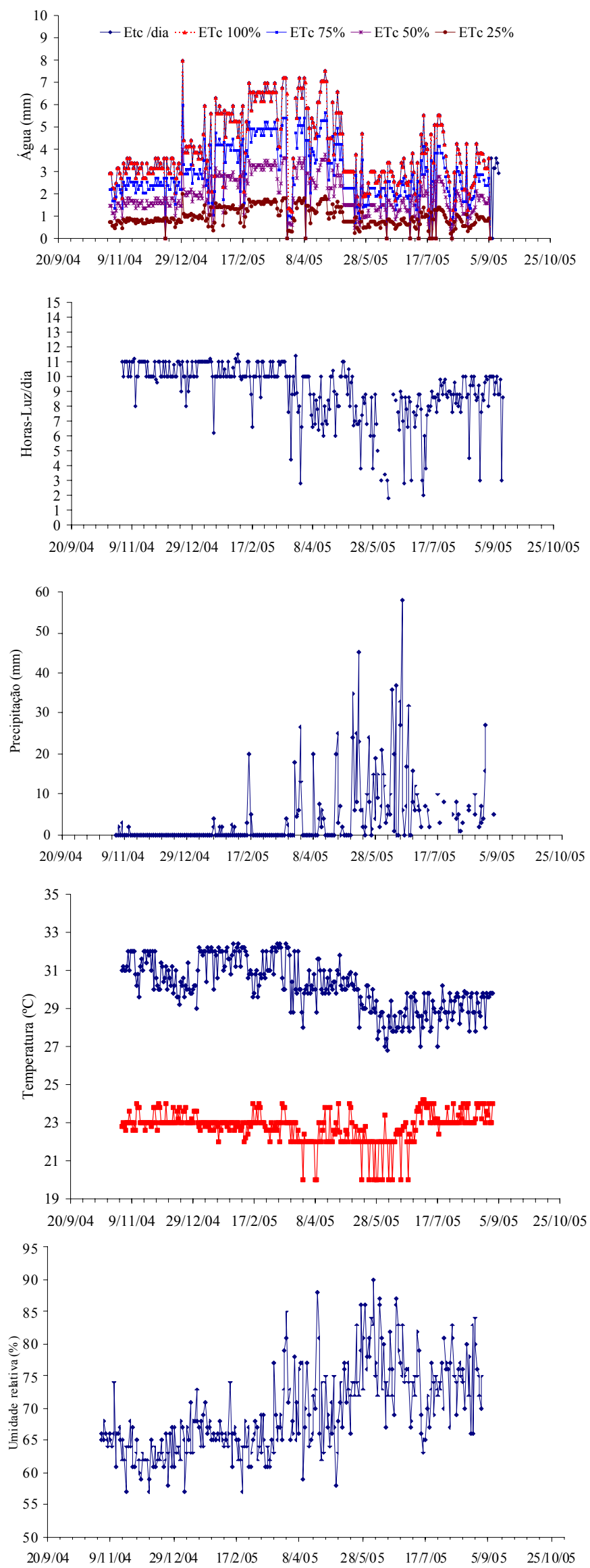

FIGURA 2. (A) Lâminas de água de irrigação; (B) horas-luz dia; (C) pluviometria (mm); (D) temperaturas máximas e mínimas; (E) umidade relativa do ar (\%) durante o período experimental. (A) Irrigation depths; (B) duration of sunlight during day; (C) rainfall; (D) maximum and minimum temperature; $(E)$ relative humidity during the experimental period. 
Fez-se a primeira irrigação em um único nível nos cinco setores, de modo que todas as parcelas estivessem em capacidade de campo no início do trabalho; somente a partir daí é que se iniciou a aplicação dos tratamentos de lâmina de água. Para o balanço hídrico, a umidade do solo foi estimada abatendo-se, sempre, as chuvas efetivas. No presente estudo, baseou-se o cálculo de precipitação efetiva em dados obtidos por SILVA et al. (1994), segundo os quais, na cultura do milho, $26 \%$ da precipitação total que incide sobre a cultura são interceptados pelas folhas, ou seja, a chuva efetiva para o milho, nas condições do Planalto Central do Brasil, é de 74\%.

O manejo de irrigação deu-se com base no tanque Classe A, utilizando-se da equação: $\mathrm{ETc}=\mathrm{ETo} \mathrm{kc}$; para o qual se fez uso do kc da cultura, valores citados por DOORENBOS \& KASSAM (1979), nos diferentes estádios de desenvolvimento.

No balanço hídrico, foi computado como chuva efetiva para o sequeiro, $71 \%$ da precipitação; entretanto, para os demais tratamentos, calcularam-se o consumo diário dentro do turno de rega (água armazenada no solo) e a precipitação pluviométrica diária; assim, a diferença entre o consumo e o que choveu configurou a lâmina de irrigação para o tratamento de $100 \%$ da ETc; para os demais tratamentos, a lâmina para a fração correspondente a 25; 50 e 75\% da ETc foi corrigida. A precipitação efetiva para os tratamentos de irrigação foi diferente e aumentou conforme diminuiu a lâmina testada; isso se deu em virtude de que grande parte das chuvas não foram efetivas para a lâmina plena de irrigação (100\% da ETc); assim, se choveu ao término de um evento de irrigação, a chuva não pôde ser computada como totalmente efetiva para essa lâmina; no entanto, parte dela foi efetiva para a lâmina de $75 \%$ da ETc e uma parte maior ainda para as canas sob tratamentos com 50 e $25 \%$ da ETc. Posto isto, o tratamento que recebeu a maior lâmina efetiva foi o de sequeiro.

\section{RESULTADOS E DISCUSSÃO}

\section{Climatologia e balanço hídrico}

$\mathrm{Na}$ Tabela 3, estão expostos os dados de lâminas de irrigação aplicadas ao longo do ano de cultivo e as respectivas precipitações efetivas calculadas. Nota-se que as precipitações totalizaram $1.100 \mathrm{~mm}$ e que o total de água aplicado nos tratamentos que receberam 25; 50 e 75 e 100\% da ETc foi bastante aproximado, devido, provavelmente, ao fato de que todo o período de inverno se deu em apenas três meses (Figura 2C).

TABELA 3. Lâmina de água de irrigação, precipitação efetiva, lâmina total aplicada à cultura e precipitação total no ano de cultivo. Depth of irrigation, effective rainfall, total water applied to the crop and total rainfall in the year of cultivation.

\begin{tabular}{ccccc}
\hline $\begin{array}{c}\text { Tratamento de } \\
\text { Irrigação }\end{array}$ & $\begin{array}{c}\text { Lâmina } \\
\text { Aplicada }(\mathrm{mm})\end{array}$ & $\begin{array}{c}\text { Precipitação } \\
\text { Efetiva }(\mathrm{mm})\end{array}$ & $\begin{array}{c}\text { Lâmina Total Aplicada } \\
\text { à Cultura (mm) }\end{array}$ & $\begin{array}{c}\text { Precipitação Total } \\
\text { no Ano de Cultivo } \\
(\mathrm{mm})\end{array}$ \\
\hline Sequeiro & 0 & 780,06 & 780,06 & \\
$25 \%$ da ETc & 256,64 & 731,31 & 987,95 & 1.100 \\
$50 \%$ da ETc & 513,29 & 487,54 & $1.000,83$ & \\
$75 \%$ da ETc & 769,93 & 243,77 & $1.013,70$ & \\
$100 \%$ da ETc & $1.026,57$ & 194,51 & $1.221,08$ & \\
\hline
\end{tabular}

\section{Efeito das lâminas de irrigação}

Apresentam-se, na Tabela 4, o resumo de ANOVA e as médias de produtividade e eficiência no uso da água (EUA) na produção de colmos e de açúcar. O efeito foi altamente significativo $(\mathrm{P}<0,01)$ para lâminas de água de irrigação e efeito significativo $(\mathrm{P}<0,05)$ para os níveis de zinco. $\mathrm{O}$ melhor ajuste deu-se por meio do modelo quadrático, estimado em função da lâmina total aplicada $(\mathrm{L}+\mathrm{PE}$ ), significativa a $1 \%$ de probabilidade (Figura 3). A diferença quanto ao uso eficiente da água, entre a cana irrigada com $100 \%$ da $\operatorname{ETc}\left(7,22 \mathrm{~kg} \mathrm{~m}^{-3}\right)$ e a cana sob regime de sequeiro 
$\left(3,99 \mathrm{~kg} \mathrm{~m}^{-3}\right)$, foi de $3,23 \mathrm{~kg} \mathrm{~m}^{-3}$; comparando-se esse resultado com o comportamento da cultura irrigada com $100 \%$ da ETc e da cana irrigada com 50\% da ETc, verifica-se não haver diferença entre a média dos tratamentos, em termos de EUA.

Para DOOREMBOS \& KASSAM (1979), a EUA na cultura da cana-de-açúcar cultivada nos trópicos e subtrópicos secos, com irrigação, em solos com $80 \%$ de água disponível (ou seja, fração de esgotamento de 20\%), varia de 5 a $8 \mathrm{~kg} \mathrm{~m}^{-3}$. Constata-se, com base nos resultados desta pesquisa, que a EUA apresentada pelos citados autores pode ser aplicada, na verdade, para a região do litoral norte-paraibano, pois a cana-de-açúcar irrigada nessa área tropical apresenta o limite médio superior de $7,22 \mathrm{~kg} \mathrm{~m}^{-3}$.

TABELA 4. Resumo de análise de variância (ANOVA), para eficiência no uso da água (EUA) na produção de colmos e de açúcar da variedade SP 79-1011, colhida aos 360 dias após a brotação. Summary of analysis of variance (ANOVA), of water use efficiency (WUE) in the production of sugarcane and sugar content of variety SP 79-1011 harvested 360 days after sprouting.

\begin{tabular}{|c|c|c|c|}
\hline \multirow[b]{2}{*}{ Fonte de Variação } & \multicolumn{3}{|c|}{ Análise de Variância } \\
\hline & $\begin{array}{c}\text { Produtividade } \\
\left(\mathrm{t} \mathrm{ha}^{-1}\right)\end{array}$ & $\begin{array}{c}\text { EUA - colmos } \\
\left(\mathrm{kg} \mathrm{m}^{-3}\right)\end{array}$ & $\begin{array}{c}\text { EUA - açúcar } \\
\left(\mathrm{kg} \mathrm{m}^{-3}\right)\end{array}$ \\
\hline & \multicolumn{3}{|c|}{ Quadrados médios } \\
\hline QMR & 32,7661 & 0,3076 & 0,0075 \\
\hline C.V. $(\%)$ & 9,04 & 8,97 & 10,40 \\
\hline Bloco/lâmina & $21,54^{\mathrm{ns}}$ & $0,2179^{\mathrm{ns}}$ & ns \\
\hline Lâmina & $7.234,33^{* *}$ & $32,30^{* *}$ & $136,61^{* *}$ \\
\hline Zinco & $120,09^{*}$ & $1,03^{*}$ & $4,43^{* *}$ \\
\hline \multirow[t]{2}{*}{ Lâmina $\mathrm{x}$ zinco } & $25,75^{\mathrm{ns}}$ & $0,16^{\mathrm{ns}}$ & $\mathrm{ns}$ \\
\hline & \multicolumn{3}{|c|}{ ANOVA e índices de regressão } \\
\hline Modelo & Quadrático & Quadrático & Quadrático \\
\hline Sig. beta 1 & 0,4893 & 0,0001 & 0,0023 \\
\hline Sig. beta 2 & 0,0001 & 0,0001 & 0,0001 \\
\hline QMDR & $13.939,24$ & 62,10 & 1,99 \\
\hline $\mathrm{F}$ & 288,62 & 169,79 & 198,22 \\
\hline \multirow[t]{2}{*}{ Prob. F } & 0,0000 & 0,0001 & 0,0000 \\
\hline & \multicolumn{3}{|c|}{ Médias para lâminas de água de irrigação } \\
\hline Sequeiro & 31,13 & 3,99 & 0,44 \\
\hline $25 \%$ ETc & 52,54 & 5,31 & 0,68 \\
\hline $50 \%$ ETc & 72,29 & 7,13 & 0,99 \\
\hline $75 \%$ ETc & 72,37 & 7,21 & 0,98 \\
\hline \multirow[t]{2}{*}{$100 \%$ ETc } & 88,10 & 7,22 & 1,06 \\
\hline & \multicolumn{3}{|c|}{ Médias para os níveis de zinco } \\
\hline 0 & 60,37 & 5,89 & 0,78 \\
\hline 1 & 62,42 & 6,10 & 0,81 \\
\hline 2 & 64,25 & 6,27 & 0,85 \\
\hline 3 & 67,69 & 6,57 & 0,90 \\
\hline 4 & 61,75 & 6,03 & 0,81 \\
\hline
\end{tabular}

QMR - quadrado médio do resíduo; QMDR - quadrado médio devido à regressão; C.V.(\%) - coeficiente de variação; Prob $>$ F - significância do Teste F (valores entre zero e 0,01 são significativos a $1 \%$; valores entre 0,01 e 0,05 são significativos a $5 \%) ; *$ - significativo a $1 \%$; ** - significativo a $5 \%$.

Esta pesquisa leva o debate para uma faixa mais ampla de EUA, incluindo, também, a cana-de-açúcar cultivada em regime de sequeiro. Verifica-se, nas condições climáticas vigentes no período do experimento (safra 2005/2006), que a cana de sequeiro utilizou $780 \mathrm{~mm}$ de água (proveniente das precipitações efetivas) de forma insatisfatória, apresentando, ao final do ano de 
cultivo, valores muito baixos de EUA $\left(3,99 \mathrm{~kg} \mathrm{~m}^{-3}\right)$, caso em que a EUA foi influenciada pela distribuição temporal da precipitação. A má distribuição e a alta concentração das chuvas em curto período (Figura 2C) foram as causas da baixa EUA pela cana de sequeiro.

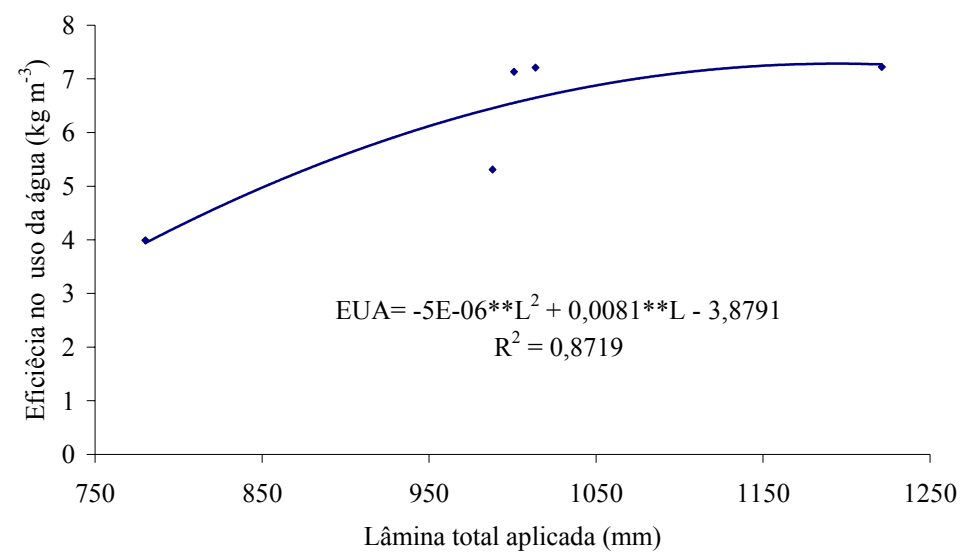

FIGURA 3. Eficiência no uso da água $\left(\mathrm{kg} \mathrm{m}^{-3}\right)$ em função da lâmina total de água. Water use efficiency $\left(\mathrm{kg} \mathrm{m}^{-3}\right)$ as a function of the total depth of water.

\section{Efeito dos níveis de zinco}

Na Figura 4, apresenta-se graficamente o comportamento da cultura em relação aos diferentes níveis de zinco pela equação de ajuste quadrático, significativa $(\mathrm{P}<0,05)$, estimando-se em $2,38 \mathrm{~kg} \mathrm{ha}^{-1}$ o nível de zinco que maximiza a EUA (Znm).

CARRIJO et al. (2004) citam que os nutrientes com forte interação com a matriz do solo se movimentam, predominantemente, por difusão, como é o caso do zinco. Segundo os autores, o aumento da umidade do solo com a utilização de tecnologia de irrigação por gotejamento aumenta a eficiência da adubação, sobretudo em solos arenosos; esclarecem, também, que tal fato ocorre por ocasião da concentração do fertilizante na região de maior umidade e de maior concentração das raízes, e, ainda, que a umidade proporciona maior disponibilidade do nutriente para a planta e favorece sua movimentação no solo.

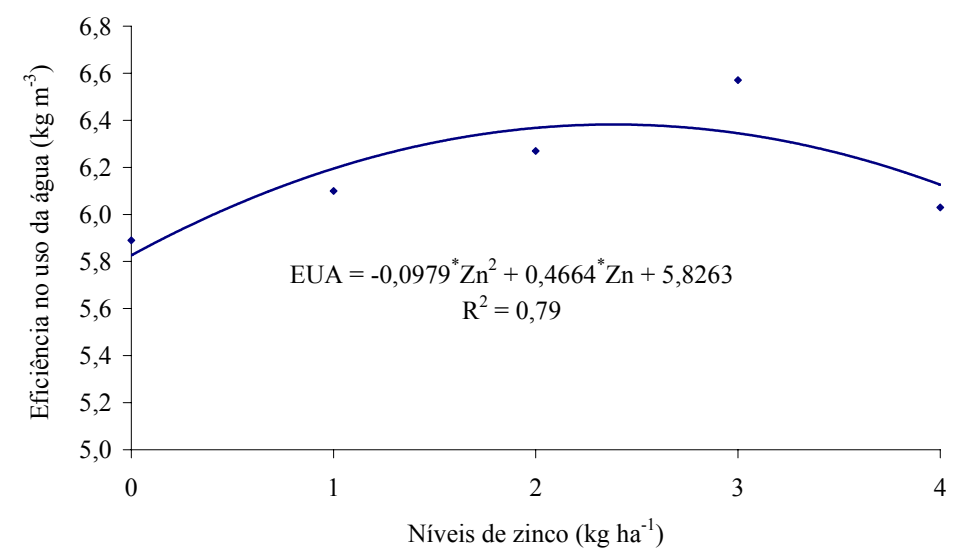

FIGURA 4. Eficiência no uso da água $\left(\mathrm{kg} \mathrm{m}^{-3}\right)$ na cana-de-açúcar, variedade SP 79-1011, em função de níveis de zinco. Water use efficiency $\left(\mathrm{kg} \mathrm{m}^{-3}\right)$ in the sugarcane variety SP 79-1011 as a function of zinc levels.

$\mathrm{Na}$ falta de dados sobre a cana-de-açúcar, apresentam-se, a seguir, informações sobre efeito de Zn em espécies da mesma família, como auxiliar na discussão de seus efeitos sobre rendimento e produção dessas culturas. Em estudos com arroz, BARBOSA FILHO (1987) verificou que a deficiência de zinco traz como conseqüência o encurtamento do internódio, reduzindo o 
crescimento. Para TAIZ \& ZEIGER (2002), o zinco é constituinte da enzima álcool desidrogenase, e é exigido para a síntese de clorofila, sendo também essencial para a biossíntese do ácido 3-indolacético (AIA), conhecido regulador de crescimento, sendo essa uma justificativa para a redução do crescimento da planta.

Estudando as interações entre zinco, boro e nitrogênio na produtividade do milho, SOARES (2003) não constatou interferência desse micronutriente em índices como: número de folhas, índice de área foliar, comprimento do primeiro internódio do colmo e matéria seca do pendão; não foram verificados, também, efeitos sobre os componentes de produção e produtividade na cultura do milho.

\section{Efeito conjunto de lâmina de água e nível de zinco}

O modelo contendo duas variáveis independentes favorece a visualização do comportamento da cultura de forma mais ampla. Com esse tipo de análise, são observados os limites máximo e mínimo, não com base na média de um fator isolado, mas, sim, nos dados médios dos dois fatores conjuntamente, favorecendo estimativa mais próxima da realidade.

Neste trabalho, não foi significativa a interação entre lâminas e zinco (Tabela 4) para EUA. Assim, optou-se por estudar o seu efeito, como facultam alguns procedimentos estatísticos (UFV, 2000; FERREIRA, 2000). Analisou-se o efeito conjunto de ambos os fatores, por meio de regressão múltipla, com disposição dos dados na Tabela 5. Na Figura 5, apresenta-se graficamente o comportamento da cultura quanto à EUA na produção de colmos, face aos tratamentos estudados (lâminas de irrigação mais precipitação efetiva e níveis de zinco). Observa-se que, quanto maior a lâmina total aplicada, maior também a resposta da cultura ao zinco, em termos de EUA na produção da matéria-prima. Da análise do modelo, depreende-se que os coeficientes lineares de lâmina de água e de níveis de zinco têm efeito positivo, enquanto os quadráticos têm valores negativos. A lâmina que maximiza a EUA ( $\mathrm{Lm}_{\mathrm{EUA}}$ ) em produção de colmo é 1.175,25 mm, enquanto o nível de zinco que maximiza (ZnmeUA a EUA é $2,38 \mathrm{~kg} \mathrm{ha}^{-1}$. Do modelo estudado, observa-se que a EUA, para a produção de colmos da cana-de-açúcar, é de $7,12 \mathrm{~kg} \mathrm{~m}^{-3}$, sendo, portanto, os valores encontrados muito próximos aos valores citados por DOORENBOS \& KASSAM (1979).

A Figura 6 é a representação gráfica do modelo exposto na Tabela 6, com dados de ANOVA da função de resposta para EUA na produção de açúcar. Por meio do modelo, altamente significativo $(\mathrm{P}<0,01)$, pode-se estimar a quantidade de açúcar produzida por cada metro cúbico de água total incidida na cultura.

TABELA 5. Regressão múltipla (lâmina de água e nível de zinco) para eficiência no uso da água da cultura da cana-de-açúcar variedade SP 79-1011. Multiple regression (water depth and zinc level) for water use efficiency of sugarcane crop (variety SP 79-1011).

\begin{tabular}{|c|c|c|c|c|}
\hline \multirow{3}{*}{ Coeficientes } & \multicolumn{4}{|c|}{ Modelo de função de produção } \\
\hline & \multicolumn{4}{|c|}{ EUA em colmo $(\mathrm{L}, \mathrm{Zn})=a+b^{*} \mathrm{~L}+c^{*} \mathrm{~L}^{2}+d^{*} \mathrm{Zn}+e^{*} \mathrm{Zn}^{2}$} \\
\hline & & Valor & Teste $\mathrm{T}$ & Prob $>$ T \\
\hline $\bar{a}$ & Constante & $-0,210718 \times 10^{2}$ & & \\
\hline$b$ & Lâmina & $0,470107 \times 10^{-1}$ & 5,8096 & 0,0001 \\
\hline$c$ & Lâmina $^{2}$ & $-0,197304 \times 10^{-4}$ & $-4,8966$ & 0,0001 \\
\hline$d$ & Zinco & $0,471841 \times 10$ & 1,9764 & 0,0241 \\
\hline e & Zinco $^{2}$ & $-0,991202 \times 10^{-1}$ & $-1,7319$ & 0,0416 \\
\hline \multicolumn{5}{|c|}{ Análise de variância do modelo } \\
\hline$\overline{\mathrm{R}^{2}}$ & & 0,68 & & \\
\hline QM & & 25,6022 & & \\
\hline Teste F & & 37,22 & & \\
\hline Prob $>$ F & & 0,0000 & & \\
\hline
\end{tabular}




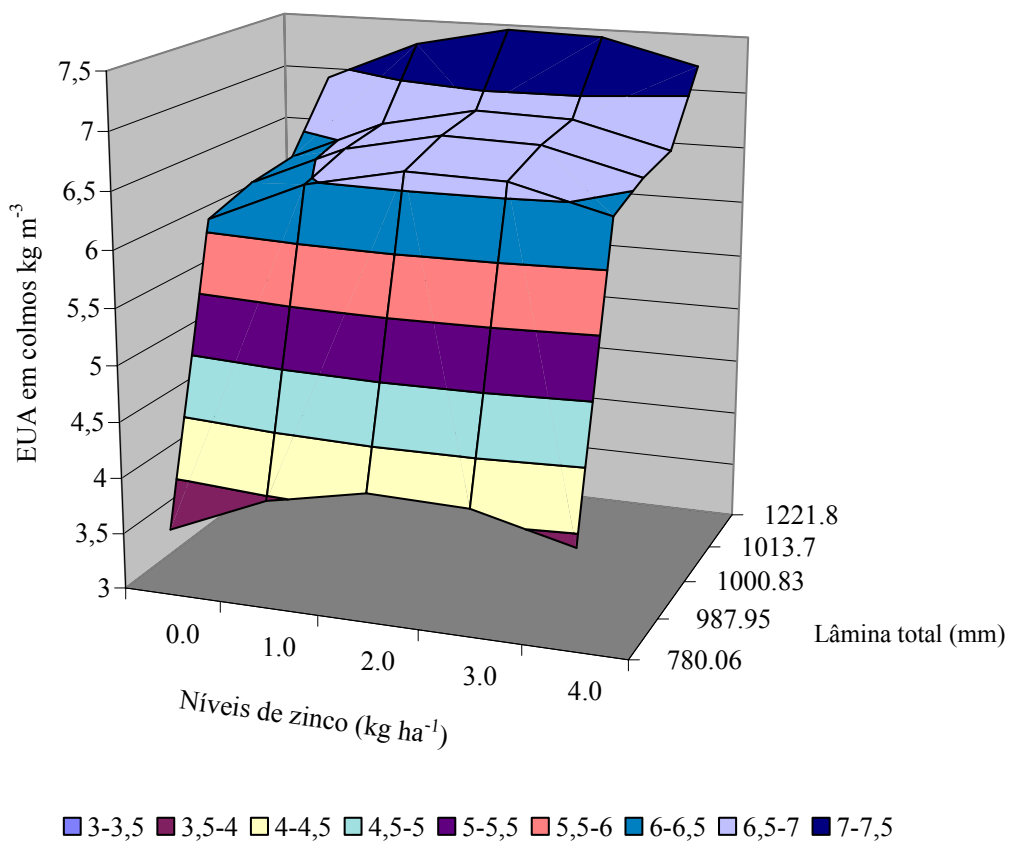

FIGURA 5. Eficiência no uso da água (EUA) na cana-de-açúcar, em função da lâmina total de água aplicada e dos níveis de zinco. Water use efficiency (WUE) in the sugarcane crop as a function of the total depth of water applied and zinc levels.

Do mesmo modelo, depreende-se que a lâmina que maximiza a EUA para a produção de açúcar $\left(\mathrm{Lm}_{\mathrm{EUAç}}\right)$ é 1.276,29 mm, enquanto o nível de zinco que a maximiza para a produção de açúcar $\left(\mathrm{Znm}_{\mathrm{EUAç}}\right)$ é $2,48 \mathrm{~kg} \mathrm{ha}^{-1}$; dessa forma, tem-se que a produtividade maximizada de açúcar é de $0,67 \mathrm{~kg} \mathrm{~m}^{-3}$. O resultado apresentado nesta pesquisa, em termos de açúcar, é semelhante ao citado por DOORENBOS \& KASSAM (1979), ao afirmarem que, para o cultivo da cana-de-açúcar com irrigação, nos trópicos e subtrópicos secos, a EUA para a produção de sacarose varia de 0,6 a $1 \mathrm{~kg} \mathrm{~m}^{-3}$.

TABELA 6. Regressão múltipla (lâmina de água e níveis de zinco) para eficiência no uso da água na produção de açúcar, pela cultura da cana-de-açúcar, variedade SP 79-1011. Multiple regression (water depth and zinc levels) for water use efficiency in the production of sugar for the sugarcane, crop variety SP 79-1011.

\begin{tabular}{|c|c|c|c|c|}
\hline \multirow{3}{*}{ Coeficientes } & \multicolumn{4}{|c|}{ Modelo de função de produção } \\
\hline & \multicolumn{4}{|c|}{ EUA em açúcar $(\mathrm{L}, \mathrm{Zn})=a+b^{*} \mathrm{~L}+c^{*} \mathrm{~L}^{2}+d^{*} \mathrm{Zn}+e^{*} \mathrm{Zn}^{2}$} \\
\hline & & Valor & Teste $\mathrm{T}$ & Prob $>\mathrm{T}$ \\
\hline $\bar{a}$ & Constante & $-0,334223 \times 10^{1}$ & & \\
\hline$b$ & Lâmina & $0,689297 \times 10^{-2}$ & 5,201040 & 0,0001 \\
\hline$c$ & Lâmina $^{2}$ & $-0,272791 \times 10^{-5}$ & $-4,133535$ & 0,0001 \\
\hline$d$ & Zinco & $0,827495 \times 10^{-1}$ & 2,116349 & 0,0172 \\
\hline e & Zinco $^{2}$ & $-0,166698 \times 10^{-1}$ & $-1,778388$ & 0,0377 \\
\hline \multicolumn{5}{|c|}{ Análise de variância do modelo } \\
\hline $\mathrm{R}^{2}$ & & 72 & & \\
\hline QM & & 0,856056 & & \\
\hline Teste F & & 46,40 & & \\
\hline Prob $>F$ & & 0,0000 & & \\
\hline
\end{tabular}




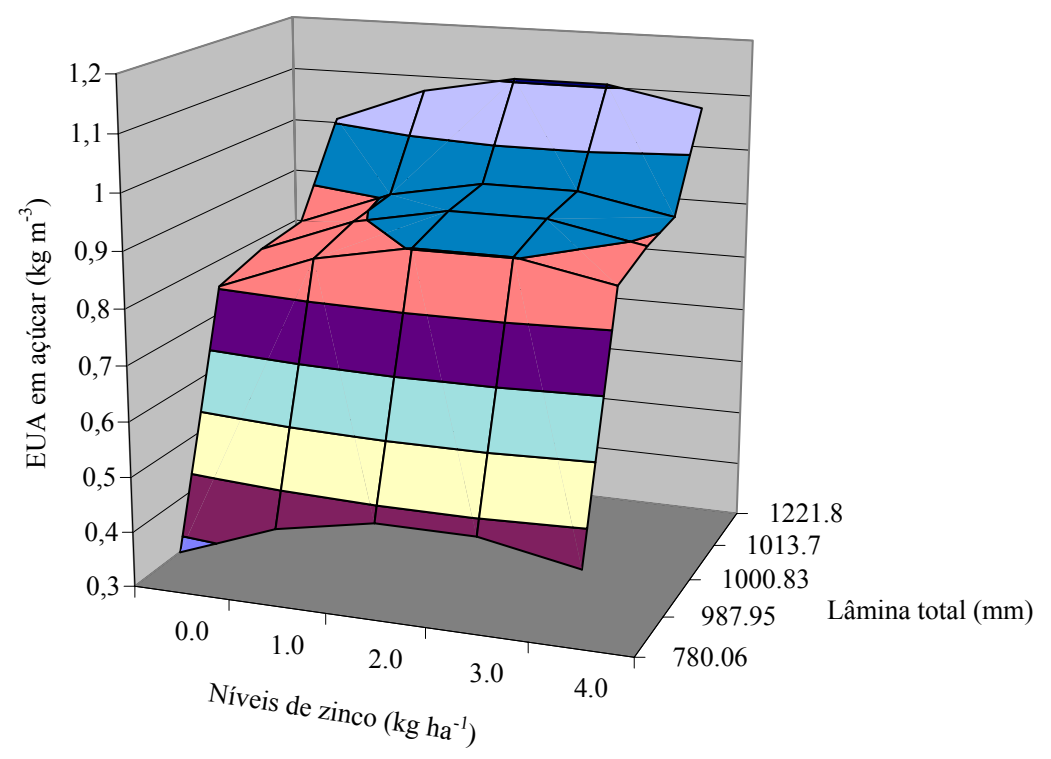

$\square 0,3-0,4 \square 0,4-0,5 \square 0,5-0,6 \square 0,6-0,7 \square 0,7-0,8 \square 0,8-0,9 \square 0,9-1 \square 1-1,1 \square 1,1-1,2$

FIGURA 6. Eficiência no uso da água (EUA) na cana-de-açúcar, na produção de açúcar, em função da lâmina total aplicada e dos níveis de zinco. Water use efficiency (WUE) in the sugarcane crop for production of sugar as a function of total depth of water applied and zinc levels.

\section{CONCLUSÕES}

Eficiência no uso da água por parte da cana-de-açúcar, na produção de colmos e de açúcar, varia com os níveis de zinco e de água total aplicada à cultura.

Para a região dos tabuleiros costeiros norte-paraibano, pode ser utilizada a EUA na produção de colmo e de açúcar como parte do planejamento estratégico para a irrigação de cultivares mais eficientes no uso de água.

\section{AGRADECIMENTOS}

À Destilaria Miriri S.A. e à União Agrícola Ltda., por todo o apoio, incentivo e fomento à pesquisa; ao Dr. Gilvan Celso Cavalcanti de Morais Sobrinho, seu Diretor Superintendente, um líder visionário à frente de seu tempo.

\section{REFERÊNCIAS}

ALFONSI, R.R.; PEDRO JÚNIOR, M.J.; BRUNINI, O.; BARBIERI, V. Condições climáticas para a cana-de-açúcar: cana-de-açúcar: cultivo e utilização. In: PARANHOS, S.B. (Coord). Cana-deaçúcar: cultivo e utilização. Campinas: Fundação Cargill, 1987, v.1, p.42-55.

BARRACLOUGH \& CO. Audit of water \& irrigation use efficiencies on farms within the Queensland horticultural industry. Queensland, 1999. $174 \mathrm{p}$.

BARBOSA FILHO, M.P. Nutrição e adubação do arroz: sequeiro e irrigado. Piracicaba: POTAFÓS, 1987. 120 p. (Boletim Técnico)

BLACKBURN, F. Sugar-cane. New York: Longman, 1984. 414 p.

CARRIJO, O.A.; SOUSA, R.B. de; MAROUELLI, W.A.; ANDRADE R.J. de. Fertirrigação de hortaliças. Brasília: Embrapa Hortaliças, 2004.13 p. (Circular Técnica, 32)

DOORENBOS, J.; KASSAM, A.H. Yield response to water. Rome: FAO, 1979. 193 p. (Irrigation and Drainage, 33). 
EMBRAPA. EMPRESA BRASILEIRA DE PESQUISA AGROPECUÁRIA. Sistema brasileiro de classificação de solos. Rio de Janeiro, 1999. 412 p.

FERREIRA, P.V. Estatística experimental aplicada à Agronomia. 3.ed. Maceió: EDUFAL, 2000. $419 \mathrm{p}$.

HATE, M.G.; ORCUTT, D.M. The physiology of plant under stress. New York: John Wiley and Sons, 1987. $250 \mathrm{p}$.

KRAMER, P.J. Water relations of plants. New York: Academic Press, 1983. 489 p.

NUNES JÚNIOR, D.; PINTO, R.S.A.; KIL, R.A. Indicadores de desempenho da agroindústria canavieira: safra 2002/2003. Brasília: Grupo IDEA, 2003. 95 p.

PÁEZ, A.; GONZÁLES, M.E.; YARUSQUI, O.X. Water stress and clipping management effects on guinea grass: I Growth and biomass allocation. Agronomy Journal, Madison, v.87, p.698-707, 1995.

RIDESA. Programa de melhoramento genético da cana-de-açúcar: variedades RB. Recife: UFRPE/EECA, 2003. 256 p. Relatório Anual

SILVA, C.L.A.; RAMOS, M.M.; FERREIRA, P.A.; SEDIYAMA; G.C.; LOUREIRO, B.T. Modelagem da precipitação efetiva na cultura do milho. Pesquisa Agropecuária Brasileira, Brasília, v.29, n.6, p.929-37, 1994.

SOARES, M.A. Influência de nitrogênio, zinco e boro e de suas respectivas interações no desempenho da cultura do milho (Zea mays L.). 2003. 92 f. Dissertação (Mestrado em Fitotecnia) Escola Superior de Agricultura "Luiz de Queiroz”, Universidade de São Paulo, Piracicaba, 2003.

TAIZ, L.; ZEIGER, E. Plant physiology. Redwood City: Benjamin/Cummings, 2002. 565 p.

UFV. UNIVERSIDADE FEDERAL DE VIÇOSA. Sistema de Análises Estatísticas e Genética: manual do usuário. Versão 8, Viçosa: FUNARBE, 2000.142 p. 